\title{
Evaluation of the optimum conditions for a local ventilation system in connection with the mine ventilation network
}

\author{
D-K Lee Korea Institute of Geoscience and Mineral Resources, South Korea
}

\begin{abstract}
In a single working face in an underground mine, a single duct and a booster fan are installed to provide fresh air to the working face for local ventilation. Since this local ventilation is provided in conjunction with the entire ventilation network of the mine, its performance and resulting environment depend on the conditions of air intake and exhaust, the duct leakage, and the fan characteristics. To operate an effective ventilation system, the optimal ventilation conditions should be identified along with the characteristics of the mine development. In this study, a computational analysis was conducted considering the ventilation method, conditions of the duct and the fan for a selected test mine scenario to provide an effective and economical local ventilation system. The resulting optimum local ventilation conditions suggested were based on an evaluation of these characteristics.
\end{abstract}

Keywords: mine ventilation, numerical modelling, auxiliary ventilation, duct

\section{Introduction}

In a single dead-end drift working area, ducting and a fan are utilised to provide auxiliary ventilation. These systems are classified into forcing, exhausting and overlap arrangements according to the layout of the duct and fan. The selection of a forcing or an exhausting system vary depending on the type of contaminants to be controlled (McPherson 1993). A range of studies has been carried out on an auxiliary ventilation system for a single drift. Onder (2002) and Mirakovski and Krstev (2000) conducted a study on the selection of fan and the fan's location in the auxiliary system of a single drift with a long length. Tuck and Naser (2005) and Lee (2011) analysed the flow characteristics according to dimension and location of a duct, and the conditions of working area in a single drift using computational fluid dynamics (CFD). Auxiliary ducts used in a mine contain many joints, which makes it impossible to prevent air leakage (Vutukuri 1987). This has generated a range of studies into leakage (Vutukuri 1984; Calizaya \& Mouset-Jones 1997; Miller et al. 2017). Like these, studies on the auxiliary ventilation system of a single dead-end drift have focused mostly on the improvement of ventilation in the drift and working areas.

This study goes beyond previous work in evaluating the effect of contaminants generated in a single drift on the entire mine. It conducted computational flow analyses for a mine with what could be considered poor ventilation conditions in order to determine the optimal auxiliary ventilation arrangement. In this study, the auxiliary ventilation system characteristics considered comprised forcing or exhausting systems, the length of duct, and fan location.

\section{Methodology}

\subsection{Selecting test mine for this study}

This test mine used as the basis for this study is an underground operating iron ore mine whose development levels range from 540 to $130 \mathrm{ML}$. 'ML' represents the length unit of depth assuming the sea level reference is $0 \mathrm{ML}$. As the length for transport gradually increases, this mine is planning to establish a new hoisting shaft in order to solve the problems arising from the rising transportation cost and to increase the production rate. Establishing a new hoisting shaft requires the construction of a ramp from the bottom of the mine up to the hoisting shaft end. The ventilation shaft in this mine reaches up to $385 \mathrm{ML}$. It has a 
diameter of $2.4 \mathrm{~m}$, and is equipped with a 100 horsepower surface exhaust fan. Also, the mine has a surface portal access and a hoisting shaft, which are presumed to be connected with existing drifts.

\subsection{The test mine ventilation and the development of a computational model for the ventilation network}

Various ventilation scenarios were explored in order to identify the quantity of the optimum airflow and ventilation route for the test mine. The mine is composed of numerous drifts crossing the extent of the orebody. These drifts, 14 levels in total, are mutually connected with a vertical interval of $25 \mathrm{~m}$. In the case of existing drifts in particular, it is impossible to measure the quantity of airflow since the structure of drift networks and the location and size of ventilation raise cannot be clearly identified. However, the quantity of airflow gradually reduces as the depth of the mine deepens. Therefore, this study measured the quantity of airflow around the ramp-way where measurable air quantity quantities are present, and in the case of drifts with too little air quantity to measure, the general ventilation route was identified by assessing air direction alone via smoke tube. The measured parameters were air direction and velocity, temperature, relative humidity, atmospheric pressure, and the drift dimensions.

In order to identify the ventilation features of the test mine, a computational model of the ventilation network was developed based on mine drift characteristics using VENTSIM (Chasm Consulting 2017), a commonly used software application for ventilation analysis. Inputs to the test mine model were the size of the drifts. A common drift wall friction resistance coefficient was applied in consideration of this mine being constructed throughout with an identical blasting method. In addition, shock loss was factored in where the air direction or air velocity suddenly changed.

\section{$3 \quad$ Results}

\subsection{Ventilation experiment}

Figure 1 shows the simplified ventilation conceptual diagram indicating that air flows in from the mine portal and hoisting shaft, and flows out via the ventilation shaft. The intake air quantity at the mine portal and $205 \mathrm{ML}$ of hoisting shaft were 20.0 and $35.8 \mathrm{~m}^{3} / \mathrm{s}$ respectively, totalling $55.8 \mathrm{~m}^{3} / \mathrm{s}$. The return air quantity via the ventilation shaft and hoisting shaft connected to $255 \mathrm{ML}$ was 33.3 and $19.8 \mathrm{~m}^{3} / \mathrm{s}$ respectively, and showed a comparatively minor total flow error of $5 \%$. The notable point in Figure 1 is a recirculation flow loop by which the part of air quantity flowing from the hoisting shaft at $205 \mathrm{ML}$ returns to $255 \mathrm{ML}$ and can re-enter the shaft.

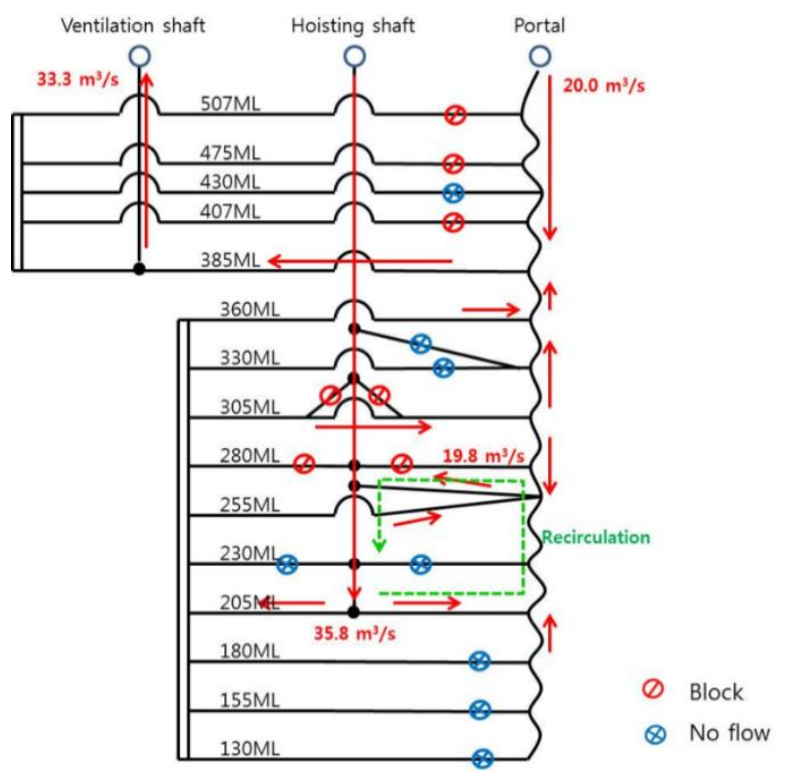

Figure 1 Ventilation conceptual diagram for test mine presented by the result of this study 
Figure 2 graphically shows, according to level depth, the delay in contaminant removal via the exhaust in the ventilation shaft. This is based on the retention time of contaminants generated on three levels: 155, 180 and $305 \mathrm{ML}$. As shown in Figure 2, as the depth of level increased (closer to the mine datum), the retention time increased. In particular, $155 \mathrm{ML}$ showed a higher retention time than $180 \mathrm{ML}$, indicating that as depth increased, the ventilation effectiveness drastically reduced.

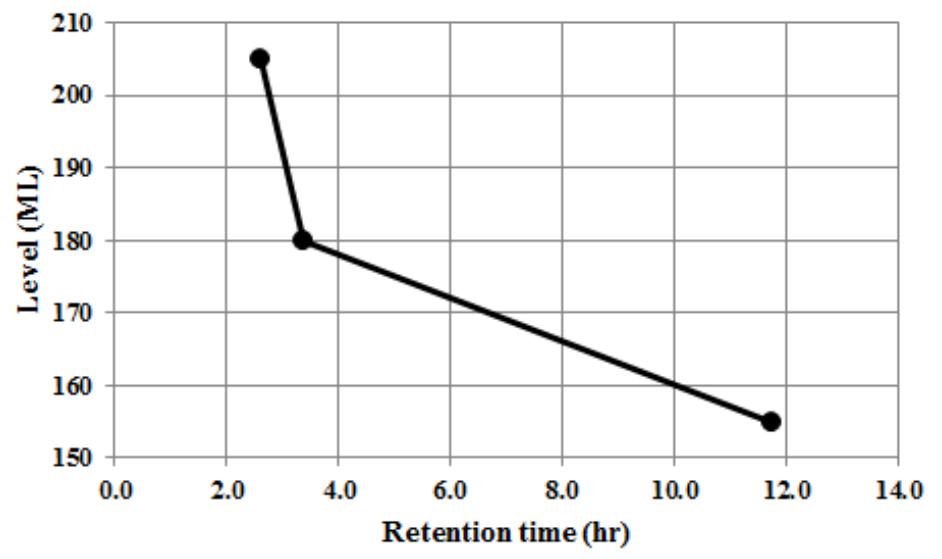

Figure 2 The variation of retention time of contaminants according to level depth of the test mine

\subsection{Selecting case studies and analysis methodology}

The methods of providing a single drift with air include a forcing system, where air is blown into the working face via a duct, an exhaust system where contaminants generated from the working face are extracted via a duct, and a combined forcing system blowing into the face with an exhaust ventilating the majority of the drift (Vutukuri 1984). The performance of these auxiliary ventilation methods are affected by the features of air flow according to ventilation ducts, the type of contaminants, and working conditions, but in the case of this test mine with poor ventilation conditions, the ventilation network features of the mine should also be considered.

This study, as shown in Figure 3, selected two ventilation ducts; one is connected from the working face of the ramp-back to the ventilation raise leading to 130 and $155 \mathrm{ML}$ (referred to as short distance, panel (a)), and the other is connected from the working face of the ramp through the ventilation system to the hoisting shaft located at $205 \mathrm{ML}$ (referred to as long distance, panel (b)). In this mine with what could be considered poor ventilation conditions, the discharge location of the duct becomes a crucial factor in conditions elsewhere. The length of a duct starting from entrance is $40 \mathrm{~m}$ in the case of short distance, and $250 \mathrm{~m}$ in the long distance option.

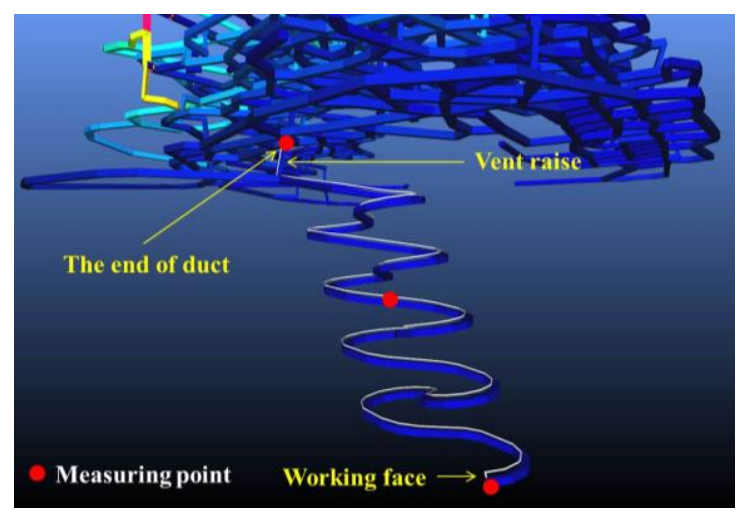

(a)

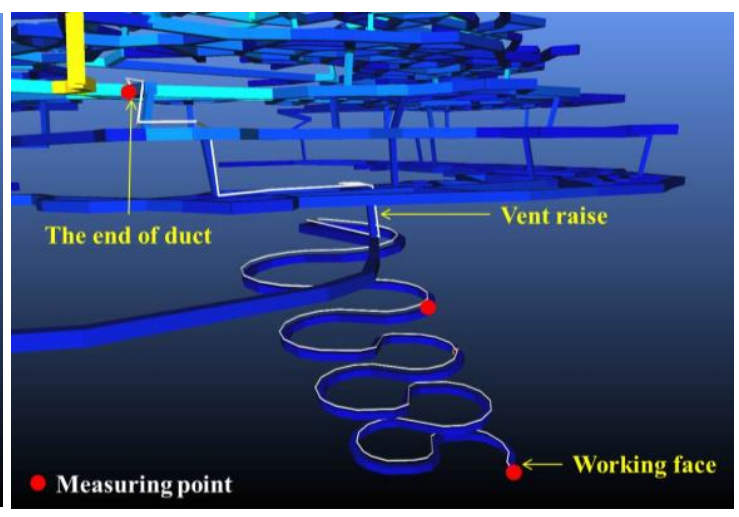

(b)

Figure 3 The location of a duct according to the length of a ventilation duct; (a) Short distance; and, (b) Long distance 
The analyses performed considered two ventilation methods: forcing and exhausting. To account for the effect of air leakage around the fan, two cases were set for the location of the fan: one is the working face, where the fan is located at the end of the drift duct to a working area, and the other is the drift entry. This study, as shown in Table 1, selected two cases, with the length of a duct, ventilation method, and the location of a fan set as variables, and conducted computational analysis in order to identify the optimal ventilation method.

Table 1 The cases of computational analysis for optimisation of auxiliary ventilation

\begin{tabular}{llll}
\hline Case & Fan location & Duct length & Ventilation method \\
\hline 1 & & Long distance & Forcing \\
2 & Working face & & Exhausting \\
3 & & Forcing \\
4 & & & Exhausting \\
\hline 5 & & Forcing distance & Exhausting \\
\hline 6 & & & Forcing \\
7 & Decline entry & & Exhausting \\
\hline 8 & & Short distance & \\
\hline
\end{tabular}

As for the analysis condition, the quantity of carbon monoxide generated when $200 \mathrm{~kg}$ of explosives were blasted in the working face of the ramp was set as standard. An unsteady analysis was then conducted by setting the condition where contaminants, after blast, have the initial concentration of 2,000 parts per million (ppm), gradually decreasing over time. The allowable maximum concentration of contaminants was set to $50 \mathrm{ppm}$, a maximum content of carbon monoxide in accordance with article 49 of the Korea Mining Safety Act (Ministry of Government Legislation 2017). The points of measuring concentration of contaminants are the working face, the half-way point along the ramp, and the entrance to the ramp at $130 \mathrm{ML}$ as shown in Figure 3.

\subsection{Concentration variations of contaminants at the working face depending on auxiliary ventilation method}

Figure 4(a) shows the concentration variations of contaminants at the working face according to the length of the duct system and the location of the fan for the forcing ventilation conditions. As shown in Figure 4, with the forcing ventilation method and the fan located at the working face, highly concentrated contaminants remained at the working face for as long as $150 \mathrm{~min}$. This is because the fan created high air velocities at the working face where high concentrations of contaminants are generated. This increased the quantity of contaminants being removed at the face. In contrast, when the fan was located at the decline entry, the contaminants with high concentration were not generated for a long time, but temporarily and intermittently at the working face. 
Figure 4(b) shows the concentration of contaminants at the working face depending on the length of a duct and the location of the fan for exhausting ventilation conditions. As shown in Figure 4(b), the behaviour of contaminants tended to be similar to that of the forcing ventilation method of Figure 4(a). The notable point here is that in the cases other than that with a short-length duct and the fan located at the ramp decline entry, the time for contaminants to be reduced was shorter in the forcing ventilation condition than in the exhausting one.

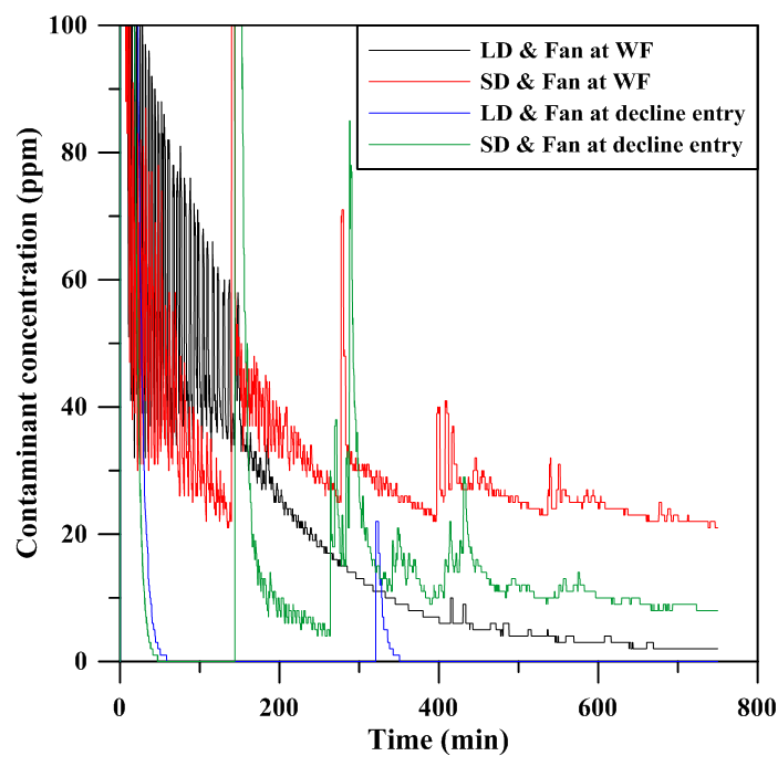

(a)

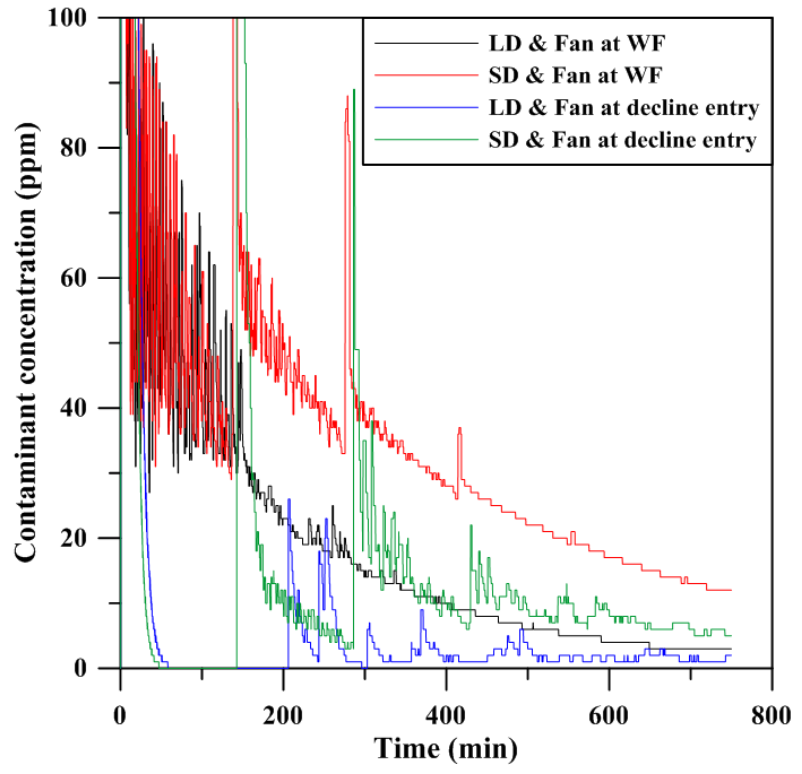

(b)

Figure 4 The concentration variation of contaminants at the working face by time. (a) Forcing ventilation; and, (b) Exhausting ventilation

\subsection{The concentration variations of contaminants at the working face according to fan location}

Figure $5(a)$ is a diagram showing concentration variations of contaminants at the working face depending on the ventilation method and the length of the duct in the case where the fan is located at the decline entry. As in Figure 5(a), the contaminants appear in the form of intermittent peak values. In this case, the concentration of contaminants is less than $50 \mathrm{ppm}$ except for the intermittent peak values.

Figure $5(b)$ represents the concentration variations of contaminants at the working face depending on the ventilation method and the length of the duct in the case where the fan is located at the working face. As in Figure $5(b)$, contaminants at the working face were present and remained at a high concentration for a comparatively long time. This is attributed to the fact that the fan located at the working face increases the air velocity of inflow or outflow around the working face, which in turn increases the quantity of air leakage, thus increasing the concentration of contaminants returning to the working face. 


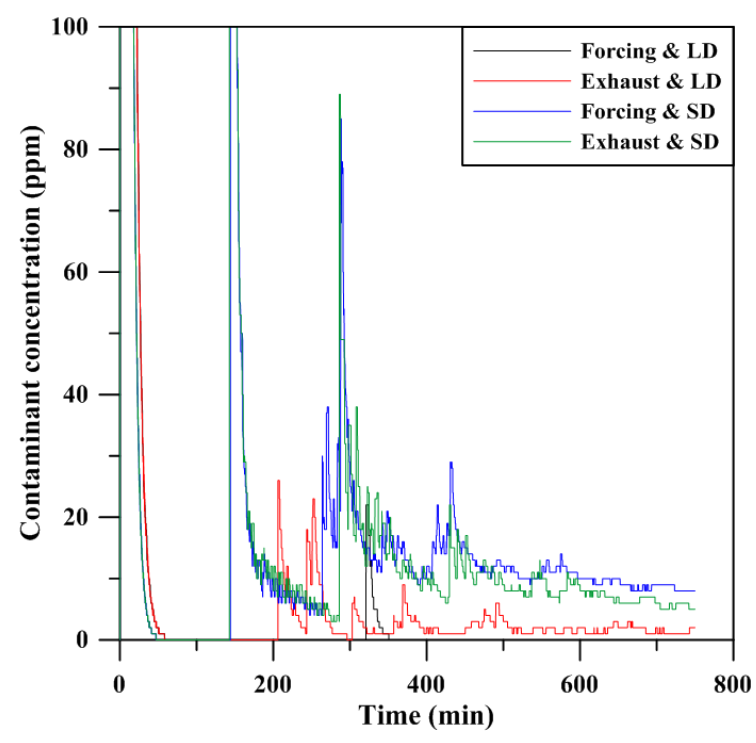

(a)

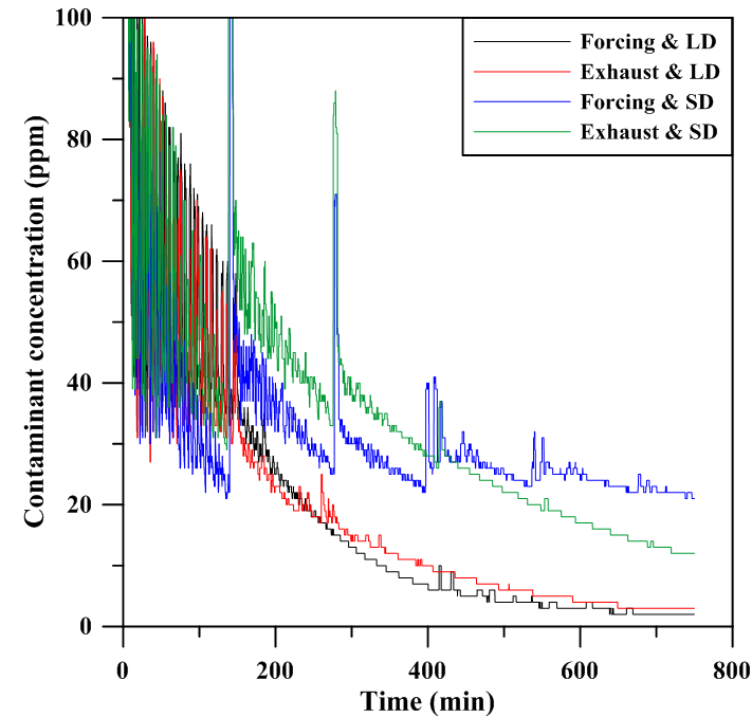

(b)

Figure 5 The concentration variations of contaminant at the working face according to the location of the fan. (a) Fan at the decline entry; and, (b) Fan at the working face

\subsection{Evaluation of the time for contaminants to reach allowable concentration and suggestion on optimal ventilation scheme}

Table 2 shows the results of the CFD evaluations on the time for contaminants to reach the allowable concentration for the selected eight cases. As in Table 2, the condition with the lowest clearance time turned out to be case 5 and case 6 where the fan is located at the decline entry with a long duct arrangement. Under this condition, both forcing and exhausting arrangements showed identical clearance times. However, as shown in Figure 4, the forcing ventilation method with case 5 showed a temporary small peak value of the concentration, whereas the exhausting ventilation method using case 6 showed a higher concentration for a comparatively long time compared to case 5 . Thus, the optimal conditions for constructing the ramp are with the fan located at the decline entry, with the long duct system back to $205 \mathrm{ML}$, and using a forcing ventilation method.

Table 2 The reduction of carbon monoxide (CO) at the working face of ramp-way by cases

\begin{tabular}{lllll}
\hline Case & Fan location & Duct length & Ventilation method & Clearance time of CO (min) \\
\hline 1 & & Long distance & Forcing & 149 \\
2 & & Exhausting & 137 \\
3 & Working face & Short distance & Forcing & 280 \\
4 & & Exhausting & 281 \\
\hline 5 & & Long distance & Forcing & 27 \\
6 & & Exhausting & 27 \\
7 & Decline entry & \multirow{2}{*}{ Short distance } & Forcing & 292 \\
8 & & & Exhausting & 288 \\
\hline
\end{tabular}




\section{$4 \quad$ Conclusions}

The low air velocity within the mine caused contaminants to be recirculated depending on the location of the duct, and concentration of contaminants was more influenced by the location of the duct and the fan than by ventilation method (forcing or exhausting).

In the case where the fan is located at the working face, the quantity of contaminants from leaking out of the duct returning to the working face increased. This kept a high concentration of contaminants at the working face for a long time. In contrast, if the fan is located at the decline entry, the quantity of leakage from the duct is small, and the wind velocity is low at the working face. This kept the concentration of contaminants comparatively low.

The conditions under which the clearance time for contaminants is the shortest were when the fan was located at the decline entry and with the long duct arrangement. As for the ventilation method, the forcing method showed a lower concentration of contaminants for a comparatively shorter time than the exhausting method. Consequently, when constructing the ramp in the lower part of the test mine, the optimal conditions were with the fan located at the decline entry, with the longer duct, and a forcing ventilation system.

\section{Acknowledgement}

This research was supported by the Research Project (17-3211-1) of the Korea Institute of Geoscience and Mineral Resources (KIGAM) funded by the Ministry of Science, ICT and Future Planning of Korea and Ministry of Trade, Industry and Energy of Korea.

\section{References}

Calizaya, F \& Mousset-Jones, P 1997, 'Estimation of leakage quantity for long auxiliary ventilation systems', in RV Ramani (ed.) Proceedings of the 6th International Mine Ventilation Congress, Society for Mining, Metallurgy, and Exploration, Littleton, pp. 475-478.

Chasm Consulting 2017, VENTSIM, Chasm Consulting, Capalaba, viewed 27/4/2017, http://www.ventsim.com

Lee, DK 2011, 'A computational flow analysis for choosing the diameter and position of an air duct in a working face', Journal of Mining Science, vol. 47, no. 5, pp. 664-674.

McPherson, MJ 1993, Subsurface Ventilation and Environmental Engineering, Chapman \& Hall, London.

Millar, D, Levesque, M \& Hardcastle, S 2017, 'Leakage and air flow resistance in mine auxiliary ventilation ducts: effects on system performance and cost', Transactions of the Institutions of Mining and Metallurgy: Section A, vol. 126, no. 1, pp. 10-21.

Ministry of Government Legislation 2017, viewed 16/5/2017, http://www.moleg.go.kr

Mirakovski, DG \& Krstev, B 2000, 'Design process and equipment selection for auxiliary ventilation systems', in GN Panagiotou \& TN Michalakopoulos (eds), Proceedings of the Ninth International Symposium on Mine Planning and Equipment Selection, A.A. Balkema, Rotterdam, pp. 89-93.

Onder, M 2002, 'Selection of fan or fan location in ventilation of long drivages and the effect of recirculation on fan number', in GN Panagiotou \& TN Michalakopoulos (eds), Proceedings of the Ninth International Symposium on Mine Planning and Equipment Selection, A.A. Balkema, Rotterdam, pp. 105-110.

Tuck, M \& Naser, J 2005, 'A three-dimensional simulation of mine ventilation using computational fluid dynamics', in DS Gillies (ed.), Proceedings of the 8th International Mine Ventilation Congress, Australasian Institute of Mining and Metallurgy, Melbourne, pp. 489-491.

Vutukuri, VS 1984, 'Design of auxiliary ventilation systems for long drivages', Proceedings of the Fifth Australian Tunneling Conference, Institution of Engineers, Sydney, pp. 73-79.

Vutukuri, VS 1987, 'Design of auxiliary ventilation systems for long drivages', Transactions of the Institution of Engineers, CE29. 
